\section{An assessment of private General Practitioners contract- ing for public health services delivery in O.R. Tambo District, South Africa}

\author{
Charles Hongoro, ${ }^{1-4}$ I \\ Itumeleng N. Funani, ${ }^{2}$ Wezile Chitha, ${ }^{2}$ \\ Lizo Godlimpi ${ }^{2}$ \\ 1Population Health, Health Systems and \\ Innovation, Human Sciences Research \\ Council, Pretoria; ${ }^{2}$ Albertina Sisulu \\ Centre for Global Health and Research, \\ Faculty of Health Sciences, Walter Sisulu \\ University, Mthatha; ${ }^{3}$ Department of \\ Environmental Health, Faculty of Science, \\ Tshwane University of Technology; \\ ${ }^{4}$ School of Health Systems and Public \\ Health, Faculty of Health Sciences, \\ University of Pretoria, South Africa
}

\section{Abstract}

Low- and middle-income countries are striving towards universal health coverage in a variety of ways. Achieving this goal requires the participation of both public and the private sector providers. The study sought to assess existing capacity for independent general practitioner contracting in primary care, the reasons for the low uptake of government national contract and the expectations of general practitioners of such contractual arrangements. This was a case study conducted in a rural district of South Africa. The study employed both quantitative and qualitative data collection methods. Data were collected using a general practitioner and practice profiling tool, and a structured questionnaire. A total of 42 general practitioners were interviewed and their practices profiled. Contrary to observed low uptake of the national general practitioner contract, $90 \%$ of private doctors who had not yet subscribed to it were actually interested in it. Substantial evidence indicated that private doctors had the capacity to deliver quality care to public patients. However, low uptake of national contarct related mostly to lack of effective communication and consultation between them and national government which created mistrust and apprehension amongst local private doctors. Paradoxically, these general practitioners expressed satisfaction with other existing state contracts. An analysis of the national contract showed that there were likely to benefit more from it given the relatively higher payment rates and the guaranteed nature of this income. Proposed key requisites to enhanced uptake of the national contract related to the type of the contract, payment arrangements and flexibility of the work regime, and prospects for continuous training and clinical improvements. Low uptake of the national General Practitioner contract was due to variety of factors related to lack of understanding of contract details. Such misunderstandings between potential contracting parties created mistrust and apprehension, which are fundamental antitheses of any effective contractual arrangement. The idea of a one-size-fits-all contract was probably inappropriate.

\section{Introduction}

Low- and middle-income countries are striving towards universal health coverage in a variety of ways. Achieving this goal requires the participation of both public and the private sector providers. As part of the South African government strategy to introduce the National Health Insurance (NHI), the National Department of Health (NDOH) embarked on a process of Primary Health Care re-engineering. An integral part of this initiative involves an exploration of how independent general practitioners (GPs), who predominantly work in the private sector, could be engaged to provide State services. In seeking to achieve this, a national GP contract was formulated by the $\mathrm{NDOH}$, based on a contracting in mechanism in which GPs as independent providers would work in public primary health care clinics and the quality of their clinical work was to be assured by the District Clinical Specialist Team. The fee to be charged is an hourly rate as per Department of Public Service and Administration sessional rate for Medical Officers regardless of years of experience. In addition to the national contract, a service level agreement (SLA) was designed that specifically sets out the services to be offered by the GP in a particular district and the special conditions regarding the implementation of the SLA. This SLA is meant to facilitate contract management, and to govern the relationship between the District Management and the GP. ${ }^{1}$ The GP contracts were officially announced as part of Ministerial consultations on NHI in 2013, and the contract forms were uploaded on the government website. Uptake of this contract by GPs, however, has been lower than anticipated.

The debates about the potential role of private providers participating in the financing and provision of health services in low and middle income countries have a long history. ${ }^{1-}$ ${ }^{7}$ In South Africa, the idea and practice of contracting out general practitioners for public purpose is equally not new. ${ }^{8-11}$ Previous work on public and private provision showed that the success of such arrangements depends on context and how it changes over time. ${ }^{11,12}$ In the last decade the nature and form of these contractual arrangements and the expectations of a general practitioner practicing in
Correspondence: Charles Hongoro, Population Health, Health Systems and Innovation, Human Sciences Research Council, 134 Pretorius Street, 0001 Pretoria, South Africa.

Tel.: +27.12.302.2250.

E-mail: chongoro@hsrc.ac.za

Key words: General practitioners; contracting; primary care services; South Africa.

Contributions: $\mathrm{CH}$, INF, WC, conceived and designed the study; LG, participated in the fieldwork, and assisted with the data analysis; $\mathrm{CH}$, IF, WC, LG wrote the paper.

Acknowledgements: this research was supported through the UK Department of International Development's (DFID) Strengthening South Africa's Revitalized Response to AIDS and Health (SARRAH) program. We would like to thank Eastern Cape Provincial Department of Health for approving this study, and lastly the private general practitioners who agreed to participate in this study.

Conflict of interest: the authors declare no potential conflict of interest.

Received for publication: 4 January 2016.

Revision received: 26 February 2016.

Accepted for publication: 6 June 2016

This work is licensed under a Creative Commons Attribution NonCommercial 3.0 License (CC BYNC 3.0).

(C) Copyright C. Hongoro et al., 2015

Licensee PAGEPress, Italy

Journal of Public Health in Africa 2015; 6:525 doi:10.4081/jphia.2015.525

both rural and urban areas have evolved. ${ }^{13}$ Although the distribution of private general practitioners has largely remained skewed to the urban towns and areas, there is a growing number of GPs who are now working in the rural areas and more are keen to do so provided the conditions allow. This study sought to characterize existing GPs, and assess the enablers and challenges to contracting with the State as experienced in OR Tambo, a rural district in South Africa. The assessment was grounded in new institutional economics that emphasizes the role of institutions and an interdisciplinary approach founded in law, organization and economics. ${ }^{14}$ The principalagent theory framework was used to analyze the governance arrangement surrounding the GP contracting and the nature of the relationships between GPs and contracting district, the incentive structures created by these arrangements and their implications for GP's performance in service delivery. One of the contentious issues regarding the national GP contract was the question of what are the acceptable payment levels and arrangements. 
Current evidence on the impact of different payment arrangements to private providers for providing public services shows the existence of mixed payment methods. ${ }^{15,16}$

In order to improve the uptake of GP contracting, it was critical to first develop a better understanding of the underlying reasons and ascertain the potential determinants of GP contract performance as well as the type of contract (e.g. fee rates, conditions of service, training opportunities etc.); and second, to better understand operational challenges of alternative contracting model between the GPs and State. Overall, the study was meant to contribute to an understanding of the underlying factors for the low uptake of the national GP contract and to explore the conditions under which the uptake of the national contract might be enhanced.

\section{Materials and Methods}

\section{Study setting}

The study was conducted in a National Health Insurance pilot district-OR Tambo in the Eastern Cape, South Africa. OR Tambo is one of the 8 districts in the Eastern Cape Province with a population of 1.4 million people and its economy is largely based on agriculture, forestry and fishing. The majority of the people (96\%) in the district are uninsured. ${ }^{17}$ The district contributes about one tenth to provincial employment (10.65\%) and gross domestic product $(9.81 \%){ }^{18}$ In addition, the district is heavily reliant on the government and community services sector for formal employment (49.31\%). The health infrastructure consists of 1 tertiary hospital, 2 regional hospitals (including one specialist hospital), 12 district hospitals, 160 clinics, 11 community health centers, 15 mobile clinics and 52 health care posts. Per capita utilization rate at primary care level for 2010/11 was 2.8 compared to the national average of 2.4. ${ }^{18}$ As a rural district, it has a very small private sector largely made up of general practitioners, non-governmental organizations and traditional healers of various forms.

In order to profile the GPs and their practices, and to characterize existing contractual arrangements, the study focused on the following: i) demographic profile of GPs; ii) health care delivery capacity of existing GPs (human resources, equipment, information infrastructure); iii) the governance arrangements for contracting GPs including the organizational and operational arrangements for GPs; iv) the nature of the contractual arrangements including type of contract and performance specifications: service package and referral arrangements, and performance in terms of service utilizations; v) payment mechanism and levels.

\section{Study design and data collection}

This was a case study that employed both quantitative and qualitative data collection methods. Data were collected using a GP and practice profiling tool, and a structured questionnaire. The data collection tools were pretested on non-selected GPs before use. The study targeted $63 \mathrm{GPs}$ that had been identified as operating in the district. A total of $42 \mathrm{GPs}$ were interviewed and their practices profiled.

\section{Data analysis}

Data were both qualitatively and quantitatively analyzed. Quantitative data from questionnaires were analyzed using SPSS V21 and qualitative data from in-depth interviews were manually analyzed using conventional content analysis. Quantitative and qualitative results were summarized using simple descriptive statistics and selected quotes.

\section{Ethical considerations}

The study obtained ethical approval from the Walter Sisulu University Ethics Committee (REF WSU 009/2014).

\section{Results}

\section{Sample description}

Of the targeted $63 \mathrm{GPs}, 42$ were interviewed which translates to a response rate of $67 \%$. Most GPs, $57 \%(\mathrm{n}=24)$ are located in Mthatha town (urban area) and the rest were scattered across the rural sub-districts of OR Tambo districts.

\section{General practitioner profile-demo- graphics}

Of the 42 GPs interviewed, most (91\%) were African, and the mean age was 43.3 years (ranging from 30-62 years) (Table 1). All the GPs had the basic medical training; few specialized training $(n=3)$, and not more than $50 \%(\mathrm{n}=19)$ had additional professional education including HIV management, advanced life support, dispensing certificates, forensic medicine, ultra-sound use, radiology, anesthetics, advanced health management systems, child health, diabetes, and HIV/TB management.

Most general practitioners practicing in $\mathrm{OR}$ Tambo district are local graduates with a few $(n=3)$ who graduated from medical schools elsewhere. More than half of the GPs (56\%) graduated from the local university, Walter Sisulu University and rest $36.6 \%$ from Universities of Pretoria (2.4\%), Cape Town (4.9\%), KwaZulu Natal (9.8\%) and Medical University of South Africa (19.5\%).

The mean practice registration period for the GPs was 12.7 years (1-37 years). Similarly, the mean number of years registered as an independent practitioner was 11 years but this varied considerably from 1 year to 30 years. More than 50\% of the GPs in OR Tambo had been practicing in the district for more than 5 years. Of the 42 GPs interviewed, only 14 (33\%) owned the facility in which there were practicing and rest were renting the facilities. For those who owned the facilities, the mean ownership period was 8.8 years.

Table 1. Demographic profile of general practitioners interviewed.

\begin{tabular}{lc} 
Characteristic, category & Statistic \\
Gender & \\
Male & $22(52.4 \%)$ \\
Female & $20(47.6 \%)$ \\
Age (mean) & 43.3 years (30-62 years) \\
\hline Educational qualifications & \\
MBchB & $30(73.2 \%)$ \\
BSc+MBchB & $5(12.2 \%$ \\
MBchB+Diploma & $3(7.3 \%)$ \\
MBchB+MMED & $1(2.4 \%)$ \\
BSc+MBchB+MMED & $2(4.8 \%)$ \\
Years registered as an independent practitioner (mean) & $12.7(1-37)$ \\
\hline Years practicing in current location (mean) & $11.1(1-30)$ \\
Years practicing in previous location (mean) & $10.7(1-37)$ \\
Ownership of facility & \\
Yes & $14(33 \%)$ \\
No (renting) & $28(67 \%)$ \\
Number of years owning facility, mean & $8.8(1-21)$
\end{tabular}




\section{General practice profile}

The majority of the practices were registered (90.5\%) and GPs operating as Solo GPs (87.8\%), and the remainder were salaried or locum doctors (2.4\% and as group partnership (9.8\%) (Table 2). The reported mean number of patients seen by GPs per day was 31 and this widely ranged from 10 to 100 patients per day. For uninsured adults, the mean cash fee was $\mathrm{R} 311$, and this ranged from R130 to R400. The common cash fee, however, was R300. The cash fee covered consultations plus any additional services rendered such as diagnostics and medicines. The fees covered various combinations of service components, which included consultation, diagnostic tests, procedures, and medicines for those who had dispensing licenses. For uninsured children, the mean cash fee was R247.86, and this ranged from R95 to R320. However, the common cash fee was R250. The cash fee covered consultations plus any additional services rendered such as diagnostics, procedures and medicines.

The majority of GPs had a dispensing license for medicines (85.7\%), and existing licenses were renewable with only 14 (33\%) GPs indicating that their licenses were continuous (i.e. with no expiry date). The rest of the GPs had renewable licenses with variable expiry dates.

\section{General practice premises-infra- structure}

The study explored the capacity of GPs to deliver services, collect and collate relevant health information by asking questions related to human resources, medical equipment, and health information technology. The assessment of the availability of essential infrastructure, equipment and human resources at the existing facilities was used as an indicator assessment of readiness to provide the essential services required by the government.

\section{Availability of human resources}

In order to establish the human resource support for the GP at their practices the study enquired about the availability of reception- ists, practice managers, professional nurses, nursing assistants (auxiliary nurse) and enrolled nurses. All practices had at least a receptionist with the majority having one or two such support staff (78.6\%) (Table 3). A notable number of practices, 17 (41.5\%) did not have practice managers but more than half of the GP interviewed (53.7\%) acknowledged having a practice manager at the facility.

The majority (81.6\%) of the GPs reported that they did not have the services of professional nurses at their practices. Only 7 of the GPs had at least 1 professional nurse working at the practice. Over half of the GPs reported not having any nursing assistant (57.5\%); however, the rest had at least one nursing assistant. With regards to enrolled nurses, only 6 (14.3\%) GPs acknowledged having one enrolled nurse. The rest 31 (73.8\%) did not have an enrolled nurse in their practice.

\section{Availability of basic functional equipment}

The study assessed the availability of selected basic equipment based on the anticipated package of services to be delivered by a contracted GP at district level. The list was not meant to be exhaustive but indicative. Overall, all GP practices were equipped with and or had access to basic and functional equipment required to provide general practitioner services which included the following index equipment: otoscope, ophthalmoscope, electrocardiography, ultra-sound scan, spirometer, and audiometer. In addition to these index pieces of equipment, most facilities met the basic infrastructure requirements to be registered as practice settings in South Africa.

\section{Computers and Internet access}

Having appropriate health information technologies is not only important for health system performance but also for effective contract management. The participating GPs were asked if they had computers and or tablets in their practices. Of the GPs, 40 (95.2\%) had a computer and $41(97.6 \%)$ of them had access to the Internet. Access to the Internet was either in the form of a smart phone or computer (92.9\% ownership).

The available computers and or smartphones were variously used for the following activities: i) submitting claims to third party payers; ii) patient records; iii) ordering diagnostic tests; iv) reviewing diagnostic tests; v) knowledge access; vi) emails, messaging and skyping (communication).

Computers served most of the highlighted

Table 2. O.R. Tambo general practitioners profile.

$\begin{array}{lcc}\text { Characteristic } & \text { Response } & \text { Statistic } \\ \text { Practice registration } & \text { Yes } & 38(90.5 \%) \\ \text { Practice form } & \text { No } & 4(9.5 \%) \\ & \text { Solo } & 36(87.8 \%) \\ & \text { Solo with locum/salaried doctors* } & 2(2.4 \%) \\ \text { Cash fee adult uninsured } & \text { Group as partnership } & 4(9.8 \%) \\ \text { Cash fee children uninsured } & \text { Mean } & \text { R311.46 (R130-R400) } \\ & \text { Mode } & \text { R300.00 } \\ \text { Dispensing licenses } & \text { Mean } & \text { R247.86 (R95-R320) } \\ & \text { Mode } & \text { R250.00 } \\ \text { Average number of patients seen per day } & \text { Yes } & 36(85.7 \%) \\ & \text { No } & 6(14.3 \% \\ & \text { Mean } & 30.9 \\ & \text { Mode } & 30.0 \\ & \text { Mode } & 25.0\end{array}$

*Doctors who were working in a Solo practice either as locums or salaried.

Table 3. Existing human resources capacity in general practitioners practices.

\begin{tabular}{|c|c|c|c|c|c|c|c|c|}
\hline \multirow[t]{2}{*}{ Number } & \multicolumn{2}{|c|}{ Receptionists } & \multicolumn{2}{|c|}{ Practice Managers } & \multirow{2}{*}{$\begin{array}{l}\text { Professional } \\
\text { Frequency }\end{array}$} & \multirow{2}{*}{$\begin{array}{l}\text { Nurses } \\
\text { Percent }\end{array}$} & \multicolumn{2}{|c|}{ Nursing Assistants } \\
\hline & Frequency & Percent & Frequency & Percent & & & Frequency & Percent \\
\hline 0 & - & - & 17 & 41.5 & 31 & 81.6 & 23 & 57.5 \\
\hline 1 & 17 & 40.5 & 22 & 53.7 & 6 & 15.8 & 12 & 30.0 \\
\hline 2 & 16 & 38.1 & 1 & 2.4 & 1 & 2.6 & 2 & 5.0 \\
\hline 3 & 6 & 14.3 & 1 & 2.4 & - & - & - & - \\
\hline 4 & 3 & 7.1 & - & - & - & - & 2 & 5.0 \\
\hline 5 & - & - & - & - & - & - & 1 & 2.5 \\
\hline Total & 42 & 100.0 & 41 & 100 & 38 & 100 & 40 & 100 \\
\hline
\end{tabular}


purposes but smart phones were largely used for communication and not for patient record keeping, for example.

\section{Reasons for low uptake of govern- ment general practice contract}

At the time of the study, none of the GPs interviewed in the district had signed up to the National GP contract at the time of the study, and the interviews sought to assess the reasons for the slow uptake in the district of this contract, their experience with other existing government contracts and their suggestions for any future State contracts. A myriad of reasons were given for why: i) did not attend the roadshows organized in the district and therefore the details of the contract were not explained; ii) the contract was not offered to the GPs; iii) the engagement style at the meetings were more dictatorial and one's inputs were not taken into consideration; iv) the contract terms were not properly explained; v) nothing actually took off which led to my being discouraged from participating; vi) information given on NHI contract was not clear; vii) I never had clarity on certain issues; not satisfied with terms and conditions of contract; viii) remuneration not adequate.

One of the key reasons that came out clearly as to why GPs were not signing-up the national contract was that the contract was never thoroughly explained to local GPs and it appeared to them that attempts to do so were more of information sessions with very little interactions between the public officials and the potential private contractor GPs. Therefore most GPs were uncertain about the conditions of the contract. A few respondents indicated that the contract remuneration was indeed very low. A notable number of the GPs indicated that they were not offered the contract, which corroborates the aforementioned finding of lack of information about the proposed contract.

\section{Existing State contracts}

Despite the fact that most doctors did not sign the new national GP contract, the majority of the GPs acknowledged having other State contracts, 29 (70.7\%). These contracts are with the district (51.6\%), regional hospital (11.9\%), central hospital $(16.1 \%)$ or a combination of these $3(9.6 \%)$. Only 2 GPs acknowledged having service contracts with a Community Health Centre in the district.

Of those who had current State contracts, the GPs indicated that there were contracted for an average of 23.93 hours per week and this ranged from 6 hours to 80 hours. The modal hours per week were 20 hours. The daily work- ing times for the contract were: $64.3 \%(\mathrm{n}=18)$ worked from $4 \mathrm{pm}$ to $8 \mathrm{am}$ and 1 weekend $24 \mathrm{hrs}$ call per month; anytime of the day, $17.9 \%$ $(\mathrm{n}=5) ; 8$ a.m. -4 p.m., 10.7\% $(\mathrm{n}=3)$; and $7.2 \%$ $(\mathrm{n}=2)$ worked from 7 a.m. or 8 a.m. to 11 a.m. either every day or Monday to Friday.

The preferred contracted times seemed to be from $4 \mathrm{pm}$ to $8 \mathrm{pm}$ and a weekend 24 hours on-call per month. The reported mean hourly contract rate was R308.64 with a minimum and maximum of R75 and R850 respectively. The median and modal hourly rates were R287 and $\mathrm{R} 250$ respectively.

\section{Level of satisfaction with State contract}

The GPs were also asked how satisfied there were with their existing contracts and the responses were overwhelmingly positive. This is clearly surprising given the non-uptake of the $\mathrm{NHI}$ or national contract. Over $66.7 \%$ of the GP agreed or strongly agreed that there were satisfied with their existing State contracts. Only a third of them were somewhat indifferent or disagreed.

Within the existing other state contracts GPs reporting seeing, on average about 30 patients per day, ranging from 6 to 100 patients per day. The modal number of patients seen per day was 20 .

Table 4. Advantages and disadvantages of current government contract as general practitioners.

Advantages Disadvantages

Well-equipped facilities and equipment allow for a variety of cases Inability to work in the same location as own GP practice and procedures that cannot be done in GP practice (wide scope of practice)

Primary Healthcare considered rewarding

Inadequate infrastructure and equipment in some public facilities

Management of HIV/AIDS patients considered personally rewarding

Poor contract managemen

Community work rewarding in general Lack of appropriate accommodation and recreational facilities

A convenient working regime

High workload and poor referrals

Job satisfaction

There is better management of patients at facility

Shortage of staff

Can follow-up of own referred patients in hospital

Getting clinical support from colleagues and consultants

Table 5. Preferred general practitioners contract type.

\begin{tabular}{lcc} 
Preferred contract type & Frequency & Percent \\
Contracting into hospital & 9 & 24.3 \\
Contracting into clinics/CHCs as solo GP & 11 & 29.7 \\
\hline Contracting into clinics as a Group Practice & 2 & 5.4 \\
Contracting out practice as a solo GP & 5 & 13.5 \\
\hline Contracting out as a Group Practice & 7 & 18.9 \\
Contracting in OR out to Clinic/CHC as Solo GP & 2 & 5.4 \\
\hline Contracting in as Solo GP OR Contracting out as Group Practice & 1 & 2.7 \\
Total & 37 & 100.0 \\
\hline
\end{tabular}

GP, general practitioners 


\section{Perceived advantages of current State contracts}

The private GPs were asked about the advantages of their job as general practitioners in their current contracts with the State. It is important to highlight that the questions asked related to other contracts excluding the new National GP contract. The majority of the GPs indicated that working for government exposed them to a wide variety of cases and therefore were able to perform a variety of clinical interventions and procedures (Table 4). They also noted that public hospitals have staff, and certain equipment and facilities such theatres that allow for specific surgical procedures, which could not be housed under a normal GP practice arrangement. This is summarized by one GP who said: I get a wide range of experience, can do C-sections, and (it) keep (s) you updated clinically, and (therefore) do not lose skills. In addition to the availability of facilities in public institutions, doctors valued the contract regime that allowed doctors to work in public facilities after hours and one Sunday, and accommodation was variable offered to them. The good thing is that I do it after hours and one Sunday, which is convenient; accommodation is provided for night duty and nursing staff cooperate. Because of the accommodating and flexible working regime some GPs see their own patients after hours especially those patients that work during the day. Some GPs highlighted that having a contract with the State allowed them to follow up their own patients in hospitals and even referred them to sessions that they would conduct themselves. The institutional setting also allowed doctors to consult with colleagues and most importantly get clinical support from consultants.

\section{Perceived disadvantages of current contract}

The GPs were also asked about the disadvantages associated with their existing contracts and several issues were raised (Table 4). A major challenge raised was the inability of GPs to be contracted to public facilities in the same area as their own GP practice. This means that doctors have to travel significant distances to public facilities, which is not only inconvenient but also costly. Some of the rural roads are not tarred and therefore difficult to use with private cars. In addition some facilities especially primary care level facilities had inadequate facilities and equipment, which made working there difficult. Doctors expressed their dissatisfactions with how such contracts are handled by the human resources departments that tended not to communicate well with them on contract expiry, for example: Not able to work in the same area as practice $G P ;$ no proper equipment; no basic resuscitation equipment; no X-ray. When (your) contract ends, there is no (such) communication and $H R$ not helpful. Not all public health facilities provide suitable accommodation and most do not have recreational facilities for staff, which makes working in these areas difficult. The workload in most public health facilities in the district and province is very high and this problem is compounded by poor referrals, which tend to congest hospitals unnecessarily. Some public facilities in the province are characterized by poor logistical management which means that it is not unusual to experience stock out of some drugs and medical supplies, and non-functional essential equipment which delays diagnosis and treatment of patients. Shortages of staff were reported as a major constraint in the context of high workloads in some facilities. However, the working conditions were reported to vary from one facility to the other and issues of personal safety and security are a concern in some facilities. Travelling long distances; roads are terrible; safety of GP when in areas of consultation. Only, one GP reported the challenge of trying to find a balance between private practice and their public facility contract work.

\section{Suggestions for improvement of the current State contract}

The respondents were then asked what needs to be improved in their existing contracts and several suggestions were made: i) improve availability of basic equipment, drugs and medical supplies (ordering and stock management); ii) improve working conditions by employing more consultants, doctors and nurses and spread the workload; iii) improve staff time management in patient care; iv) administrative support units such as HR must improve communication with staff; v) provide decent accommodation and recreational facilities for staff; vi) improve the referral system and decongest referral hospitals; vii) provide opportunities for staff to develop themselves e.g. through further training; viii) improve remuneration.

In order to improve the working conditions in public facilities; the doctors suggested improvements in the basic infrastructure; staffing levels and mix; working ethos so that more time was spent on patient care and human resource department staff communication with front line staff; and remuneration levels and opportunities for staff development. In addition to improving the capacity of the facilities, the doctors suggested that the referral system be improved to decongest hospitals and allow only patients that need to be seen by doctors and specialists be seen at appropriate levels, and minor cases be dealt with comprehensively at primary care level.
Interest in national general practitioners contract

The overwhelming majority of GP expressed interest in signing the National GP contract if offered 37 (88.1\%). Only 5 (11.9\%) said there were not interested in signing this state contract. However, despite showing overwhelming interest in signing a state contract, the GPs highlighted several considerations they would make before signing such a contract. These included the following, not in order of importance: i) being able to be contracted to a facility within the same area as GP practice; ii) being able to follow up own patients referred to the contracted referral facility; iii) good remuneration; iv) good working conditions including provision of suitable accommodation; v) being able to visit other clinics in the area; vi) opportunities for improving own clinical skills; vii) being allowed to see public patients in their own practices as time is the main issue; viii) clarity on the role of GP in the new system and the State's responsibility in the whole system; ix) contract time must be flexible enough to allow GP to work both in their practice and public facility; $x$ ) public facilities must be accessible and have all the basic infrastructure and facilities for a doctor to function effectively.

It is clear that there was interest to sign the contract provided the working conditions and the remuneration were improved significantly. As one GP put it: I think it's unethical to sign into a system that does not work. When asked which contract type they preferred, nearly $30 \%$ of the doctors preferred to be contracted-in clinics, and community health centers followed by $24.3 \%$ who preferred to be contracted into hospitals (Table 5). A few preferred to be contracted-out as a group practice (18.9\%) and $13.5 \%$ as a solo GP.

\section{Discussion}

The findings of the study could be argued to be paradoxical given that there was low adoption of the national contract in OR Tambo district whilst at the same time there was clear evidence of interest in participating in it (90\%). It was also evident that the majority of doctors had other existing state contracts largely as sessional doctors in hospitals. The reasons proffered for low uptake varied but ultimately centered on general lack of understanding of the national contract and its governance arrangement, which manifested itself as mistrust and apprehension.

The study showed that there is sufficient number of independent doctors to be engaged to support primary care services in the district with $88 \%$ of them already operating as Solo 
GPs in strategic locations throughout the district. With a reported average of 31 patients seen per day, the proposed National Health Insurance per capita primary care utilization target of 3 to 3.5 visits per year is likely to be met through such contractual arrangements. What was also notable is the fact that the majority of the general practitioners in the districts originally come from that district and more than half of them studied at a local university. This means that the doctors fully understand their local socio-economic-cultural context and are more likely to stay in those communities if their employment and business expectations are met through the proposed national contract. Overall, the capacity to deliver clinical services on behalf of the state at primary care level was evidently available as most GP had the basic supportive human resources, equipment and health information infrastructure to even support other forms of contracting such as contracting out public patients to GP practices. For a district with a population of 1.4 million people, the possibility of having $1 \mathrm{GP}$ per 22,000 population, although normatively not ideal, it is significant for a rural district. The critical question is how these GPs would be distributed or located to ensure that they are accessible to all who need their services. Contracting provides the opportunity for the government to purchase services from GP for specific areas where there is need.

Several reasons were given us to why there was low uptake of the NHI national GP contract could be addressed by engendering trust between the government and independent GPs through adequate communication and consultations. Contracts are by nature relational and can therefore only succeed if the government is able to mutually transfer risks to independent providers. There was clearly a knowledge gap and therefore misunderstanding of the specific details of what the national contract entails. This is critical in any contractual relationship as the principal (i.e. the State) needed to ensure that the objectives and indeed provisions of the contract are fully understood by the agents (i.e. GPs) before they committed to it. It might well be that the reported limited consultations with the doctors unnecessarily created apprehension and hence mistrust of the proposed contract. The GPs were not entirely sure of the payment arrangements and levels, and neither were they aware of other forms of government support for training and travel and accommodation to sites distant from their GP practices, amongst others.

The reported experience of the private GP with other State contracts is particularly illuminating. Firstly, it showed their preferences in terms of working times in government facilities. Most of them worked after-hours, that is from $4-8$ p.m. and did one weekend 24 hrs call per month. Secondly, their hourly contract rate was R309, which is actually lower than the proposed NHI national contract hourly rates of R381 (April 2014 - 31 March 2015) or R405 (April 2015 to March 2016). Most recently, the National Department increased these rates by $22 \%$ for those working in rural districts such as OR Tambo. Thirdly, most of them had hospital contracts which gave them opportunities to deal with diverse clinical cases, engage other clinicians and get specialist support as part of their on-the-job-training, work flexible times and access specialized equipment and supportive staff. In some cases, accommodation was provided for doctors who are assigned to outlying areas. Over $50 \%$ of the interviewed doctors were satisfied with the state contract, which suggests that any such contract with independent GPs must be designed in ways that capture these features if it is to be attractive to them. Fourthly, they highlighted some perceived challenges with current state contracts particularly related to poor contract management, which is critical to the success of such public/private mix arrangements. It is one thing to have a good contract but it is another to ensure that it is effectively managed to achieve the government goals. Inadequacies in other areas such as staff, infrastructure and equipment point to the need to resource public facilities adequately so that private providers contracted-in are able to function optimally. Lastly, the reported challenge of balancing their time between public and private work points to a much larger issue related to whether or not a mix of contracting-in and contracting-out (public patients referred to GP practices) is not better than having a one-sizefits-all contractual arrangement. It is conceivable that under circumstances where an independent doctor can attend patients in his or her practice and cannot always be in designated facility, those patients could be referred to the GP practice. However, this arrangement can only work where patients do not need to travel long distances and that there is effective state capacity to monitor and ensure that contracted providers do indeed provide the services. The fees charged to non-insured patients in GP practices averaged R311 and R248 per adult and child patient respectively compared to the government's hourly rate of R405, meaning that private doctors ordinarily generate more income per hour because they treated at least one patient per hour. However, this needs to be interpreted in the context of a rural district where the majority of people do not have money and are therefore unable to always pay a cash fee. In addition, the study showed that the daily workload (and hence income) was variable amongst GPs so government income through a national contract would make a significant difference to those doctors that might not be operating optimally because of low throughput. The introduction of the $22 \%$ rural adjustment to the hourly fees introduced in 2015 is attractive by most GPs.

\section{Conclusions}

Low uptake of the national GP contract was largely due to variety of factors that can be explained by inadequate communication and consultations with the local GPs on contract details; that is, on services to be rendered, payment levels and additional compensation for related expenses such as travel, working regime, contracting-in and -out options. Misunderstandings create mistrust and apprehension, which are fundamental antitheses of an effective GP contractual arrangement. Most GP are interested in signing a National GP contract provided it is flexible and allows them to continue with their practice and the remuneration remain competitive. Engagements with them ought to be based on mutual respect whilst providing for wider contractual choices. The findings suggest that whilst GPs are interested in contracting with government, they had variable preference of contract design which means that a one-size-fits-all contract might is not advisable.

\section{References}

1. Bam N, Marcus T, Hugo J, Kinkel H-F. Conceptualizing Community Oriented Primary Care (COPC) - the Tshwane, South Africa, health post model. Afr J Prm Health Care Fam Med. 2013;5(1), Art. \#423.

2. Bennett S, McPake B, Mills A. Private providers in developing countries: serving the public interest. London and New Jersey: Zed Books; 1997.

3. Broomberg J, Masobe P, Mills A. To purchase or to provide? The relative efficiency of contracting out versus direct public provision of hospital services in South Africa. In: S. Bennett, B. McPake, A. Mills eds. Private Health Providers in developing countries: serving the public interest. London and New Jersey: Zed Books; 1997.

4. McPake B, Hongoro C. Contracting out of clinical services in Zimbabwe. Soc Sci Med 1995;41:13-24.

5. Khim K, Annear PL. Strengthening district health service management and delivery through internal contracting: lessons from pilot projects in Cambodia. Soc Sci Med 2013;96:241-9.

6. Chirwa ML, Kazanga I, Faedo G, Thomas S. Promoting universal financial protection: contracting faith-based health facilities to 
expand access-lessons learned from Malawi. Health Res Policy Syst 2013;19:1127.

7. Wang Y, Eggleston K, Yu Z, Zhang Q. Contracting with private providers for primary care services: evidence from urban China. Health Econ Rev 2013;3:1.

8. Kinghorn A. The role of general practitioners in a future national health system: experience with contracting of part-time district surgeons and suggestions for change. Johannesburg: Centre for Health Policy; 1996.

9. Chabikuli N, Schneider H, Blaauw D, et al. Quality and equity of private sector care for sexually transmitted diseases in South Africa. Health Policy Plan 2002;17:40-6.

10. Palmer N, Mills A, Wadee H, et al. A new face for private providers in developing countries: what implications for public health? Bull World Health Organ 2003;81:292-7.

11. Mills A, Palmer N, Gilson L, et al. The performance of different models of primary care provision in Southern Africa. Soc Sci Med 2004;59:931-43.

12. Mills A, Bennett S, Russell S. The challenge of health sector reform: what must governments do? New York: Palgrave; 2001.

13. Moosa S. A path to full-service contracting with general practitioners under National Health Insurance SAMJ 2014;104:155-6.

14. Williamson OE. Mechanisms of Governance. Oxford: Oxford University Press; 1996.

15. Lagarde M, Palmer N. The impact of contracting out of health outcomes and use of health services in low and middle-income countries. Cochrane Database Syst Rev 2009;4:CD008133.

16. Gosden T, Forland F, Kristiansen I, et al. Capitation, salary, fee-for-service and mixed systems of payment: effects on the behaviour of primary care physicians. Cochrane Database Syst Rev 2011;3:CD002215.

17. Massyn N, Day C, Barron 0, Haynes R, English R, Padarath A, eds. District Health Barometer. Durban: Health systems Trust. 2011/12.

18. McCann M. Eastern Cape Or Tambo District (DC15), programme of support to local economic development in the Eastern Cape, competitive advantage assessment and training project, European Consultants Organisation; 2005. 